Número Temático:

\title{
Leituras e leitores de Foucault: diálogos com a Educação
}

\section{Apresentação}

O vigor do pensamento de Foucault transcende o tempo e o espaço. A atemporalidade e a potencialidade de seu pensamento nos instigam a pensar o presente, particularmente no campo das práticas da Educação. O presente número temático tem como proposta dar visibilidade às pesquisas que tematizam o pensamento foucaultiano, colocando em debate as leituras e os leitores de Foucault. Tomamos como leituras os autores lidos por ele e que, de algum modo, influenciaram o seu pensamento: desde os gregos e romanos até os pensadores contemporâneos. Por sua vez, os leitores de Foucault constituem um campo também amplo, seja refutando ou convergindo com o seu pensamento - grupos e correntes do campo filosófico, político, econômico e cultural, entre outros -, Foucault é leitura imprescindível desde os anos 60. Assim, pretende-se que este número temático possa ampliar o debate em torno das contribuições de Foucault e das leituras e dos leitores de Foucault para se pensar a educação.

O primeiro artigo, "The sociology of education as the history of the present: fabrication, difference and abjection" (A sociologia da educação como a história do presente: fabricação, diferença e abjeção), publicado em inglês, de autoria de Thomas Popkewitz, apresenta as Ciências Sociais e Psicologia da Educação como produtoras de subjetividades a partir da tese cultural que faz com que os sujeitos ajam por si mesmos, sendo a criança uma dessas subjetividades. $\mathrm{O}$ artigo defende a tese de que a produção de subjetividades em Educação funciona de modo a dividir, diferenciar e abjetar qualidades particulares, produzindo desigualdade à medida que busca a igualdade.

O texto subsequente de Silvia Grinberg, "Dispositivos, gubernamentalidad y educación em tempos de gerenciamento conservador: un puzle para armar" (Dispositivos, governamentalidade e educação em tempos de gerenciamento conservador: um quebra-cabeça 
para montar), publicado em espanhol, discute as novas lógicas do governo da população baseadas na liberdade de fazer-se a si mesmo, entendidas como autogoverno, cuja contraparte consiste em legitimar os incluídos e os excluídos. O artigo empreende um debate conceitual em torno das noções de governamentalidade de modo a abordar a dinâmica de nossa atual era de gestão conservadora.

Nayara Dias Scrimim e Sílvio Gallo em "As redes sociais e a constituição dos sujeitos contemporâneos: um instrumento biopolítico?" problematiza o fenômeno das redes sociais e seu impacto nos processos de subjetivação - um instrumento da tecnologia de poder, da biopolítica - explicitando como, por meio dessas redes, se exerce um "racismo de Estado", que permite estabelecer o corte e a exclusão, para o exercício do controle sobre uma população e seus efeitos nos processos de subjetivação.

O artigo, "Sustentação e disciplina nas medidas socioeducativas", de autoria de Conrado Neves Sathler, traz uma análise das Medidas Socioeducativas para Crianças e Adolescentes em conflito com a lei. Essa análise identifica alguns traços do dispositivo de sustentação, conforme apontado por Winnicott, mas reconhece a prevalência do dispositivo disciplinar, descrito por Foucault. O resultado dessa política pública produzida pela legislação e pelas regularidades administrativas utilizadas em sua execução é a produção de uma subjetividade institucionalizada pelo viés do trabalho tomado como mecanismo central de normalização dos corpos e a exclusão como condição social que, ao final, retroalimenta a necessidade de endurecimento das medidas disciplinares.

O artigo de David da Silva Pereira, "Docência, escola e escolarização - uma entrevista de Michel Foucault para a Periscope em 1975", analisa um dos poucos momentos em que Foucault fala diretamente sobre a escola. Nessa entrevista a Jacques Chancel, em 10 de março de 1975, Foucault é indagado sobre a sua docência, a escola, as implicações da família em relação à escolarização, ao ambiente escolar e à atitude dos jovens na escola. Dos elementos que emergem desse diálogo, encontra-se um comparativo sobre a docência e a escola brasileira atual pela problematização de alguns elementos da formação docente e da construção da relação de ensino-aprendizagem com esse outro - o aluno.

A Biopolítica é revisitada por Rodolfo Arruda Leite de Barros no artigo "Uma leitura da biopolítica: reflexões sobre a Segurança Pública no Brasil (2006-2017)" que, por meio da análise 
das políticas de Segurança Pública, entre os anos de 2006 e 2017 no país, observou a articulação das dinâmicas de "encarceramento em massa, guerra às drogas e militarização da polícia" como produtoras de um dispositivo de controle de corpos abarcados pela ferramenta interpretativa da Biopolítica, mas, para além disso, indicou a viabilidade de complementação pela utilização dos conceitos de Tanatopolítica e Necropolítica para melhor compreensão da violência prisional.

Por meio das noções de ética e de experiência na obra de Michel Foucault, André Marcio Picanço Favacho, "A docência como experiência ética: aproximações entre os estudos foucaultianos e a prática docente", pensa sobre a experiência docente contemporânea, problematizando, a partir de projetos de docentes brasileiros submetidos a uma premiação nacional, os enunciados éticos que esses sujeitos foram capazes de produzir tanto como manifestação de ética quanto de política. As análises apontam para a experimentação de construções de sentidos para uma docência atual humanista e de resolução de problemas sociais.

O artigo, "O dispositivo de numeramentalidade: uma ferramenta conceitual, metodológica e analítica de inspiração foucaultiana", de Renata Sperrhake e Samuel Edmundo Lopez Bello, faz uma revisão sobre o conceito de dispositivo para mostrar como a Numeramentalidade pode ser entendida como um dispositivo histórico, uma grade analítica e um programa de pesquisa, salientando a potencialidade do conceito para a análise de práticas envolvendo números, quantificações, medidas e classificações, entre outras.

Seguindo a lógica da análise Biopolítica, complementada pelos conceitos de gestão Tanatopolítica e Necropolítica, Marcos Mondardo discute no artigo "Territórios de povos e comunidades tradicionais: estado de exceção, governo bio/necropolítico e retomadas de tekoha" a (des/re)territorialização do Mato Grosso do Sul. Os desdobramentos dos conflitos e disputas entre a população indígena Guarani e Kaiowá com o agronegócio indicam a condição de "exceção" desses povos e as retomadas dos Tekoha como possibilidades de devir.

O conceito de heterotopia, proposto por Michel Foucault no final dos anos 1960, é problematizado por Marcelo Vicentin e Isabel Cristina dos Santos Rodrigues em "Que rostos da escola emergem quando em frente ao espelho" a fim de discutir as relações de poder-saber presentes no campo escolar. Para tanto, a emergência e o uso desse operador conceitual por Michel Foucault, em diálogo com o conceito de rosto proposto por Giorgio Agamben, que 
possibilita a reinvenção dos espaços, das posições-sujeitos na escola contemporânea.

“Práticas de si no discurso de professores do ensino superior: diálogos entre Foucault e Hadot", de Luciana Aparecida Silva de Azeredo e Márcia Aparecida Amador Mascia, empreende uma análise discursiva de dizeres de professores do ensino superior sobre o cuidado (de si), à luz de Foucault, autores pós-foucaultianos e Hadot. O artigo constata o quão enredados estão os entrevistados nas/pelas técnicas neoliberais de governamentalidade e a importância de manter acesa a esperança na possibilidade de fazer de nossas vidas um ensaio de nós mesmos, em constante transformação, apostando na relação consigo como uma alternativa, uma forma de resistência diante do poder (pós)moderno.

O artigo "Saberes em práticas culturais: condutas e contracondutas no campo da Matemática e da Educação Matemática", de Alexandrina Monteiro e Jackeline Rodrigues Mendes, discute o Campo da Etnomatemática a partir de pesquisas e estudos que mostram a diversidade desse movimento no interior do campo da Educação Matemática, numa perspectiva foucaultiana pelo conceito de contraconduta. As autoras compreendem sua disseminação de forma rizomática, por vezes antagônicas, explicada pelas autoras pelo fato de sua raiz emergir no interior do campo estruturalista da Matemática.

"Teorias Críticas Latino-Americanas: leitores e leituras decoloniais de Foucault", de autoria de Clayton Roberto Messias e de Carlos Roberto da Silveira, analisa, na perspectiva das Teorias Críticas Latino-Americanas (TCLA's), as ideias de Michel Foucault acerca do saber colonial desde suas primeiras formulações. São colocados em debate com Foucault os pensadores decoloniais: Aníbal Quijano, Catherine Walsh, Enrique Dussel, Santiago Castro-Gómez, Ramón Grosfoguel e Walter Mignolo, entre outros. Os autores do artigo concluem que um exame mais acurado dessas questões de modo algum esgotaria as temáticas que surgissem de um debate com Foucault sobre a Colonialidade do Saber na perspectiva das Teorias Críticas LatinoAmericanas.

O artigo, "Subjetividades des(re)territorializadas no ensino de filosofia: uma análise das práticas e saberes de professores não graduados em filosofia", de Daniel Santini Rodrigues, teve como proposta pensar a contribuição da Filosofia no currículo do Ensino Médio e nos efeitos que essa presença provoca nos sujeitos-professores desta disciplina, de modo especial, os não graduados em Filosofia. O artigo fundamenta-se nos estudos de Michel Foucault, de Gilles 
Deleuze e de Félix Guattari, tematizando os seguintes conceitos: subjetividade des(re)territorializada e "escritas de si".

Encerrando esse número temático, Carolina Polezi e Anderson Luiz Barbosa Martins em "Condução e contracondução na dança de salão" põe no palco a dança de salão, a fim de refletir sobre as transformações dessa prática por meio do conceito de condução: uma ferramenta de controle do corpo da mulher pelo homem; relações de poder, constituídas na Europa do século $\mathrm{XV}$, presentes na forma de governo dessa dança social. Entretanto, os autores afirmam a contraconduta como modo de experimentação para escapar à heteronormatividade e criar novas possibilidades para a expressão e vida e outro modo de dançar a dois.

Esperamos que as discussões aqui apresentadas possam fomentar novos e outros olhares para a Educação e para as questões da sociedade contemporânea, a partir das problemáticas das teses foucaultianas na interface com seus leitores e suas leituras, materializadas nos artigos produzidos e publicados neste número temático.

Conrado Neves Sathler Marcelo Vicentin e Márcia Aparecida Amador Mascia (Organizadores) 